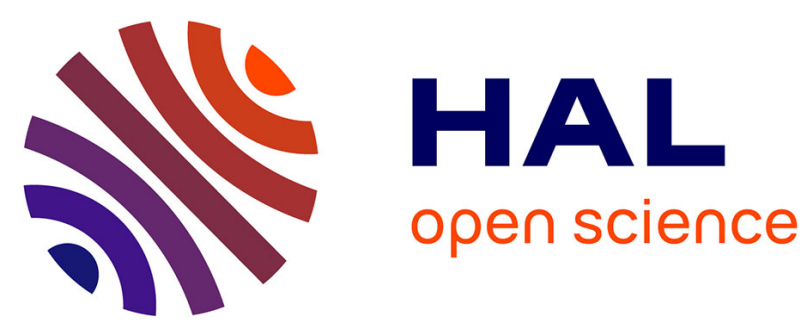

\title{
Emptying time of a tank filled up with explosive paste. Comparison between experimental measurements and predictions based on rheological characterization of the paste
}

Jean-Philippe Guillemin, Olivier Bonnefoy, Gérard Thomas, L. Brunet, N. Forichon-Chaumet

\section{To cite this version:}

Jean-Philippe Guillemin, Olivier Bonnefoy, Gérard Thomas, L. Brunet, N. Forichon-Chaumet. Emptying time of a tank filled up with explosive paste. Comparison between experimental measurements and predictions based on rheological characterization of the paste. 15th International Congress on Rheology, Aug 2008, Monterey, United States. hal-00409985

\section{HAL Id: hal-00409985 https://hal.science/hal-00409985}

Submitted on 14 Aug 2009

HAL is a multi-disciplinary open access archive for the deposit and dissemination of scientific research documents, whether they are published or not. The documents may come from teaching and research institutions in France or abroad, or from public or private research centers.
L'archive ouverte pluridisciplinaire HAL, est destinée au dépôt et à la diffusion de documents scientifiques de niveau recherche, publiés ou non, émanant des établissements d'enseignement et de recherche français ou étrangers, des laboratoires publics ou privés. 


\title{
Emptying time of a tank filled up with explosive paste. Comparison between experimental measurements and predictions based on rheological characterization of the paste
}

\author{
J.P. Guillemin(A), O. BONNEFOY(A*), G. ThOMAS(A), L. BRUNET(B), N. FORICHON- \\ CHAUMET(C)
}

(A) Ecole Nationale Supérieure des Mines de Saint-Étienne, Centre SPIN/ LPMG, UMR CNRS 5148, 158 Cours Fauriel, 42023 Saint-Étienne Cedex 2, France

(B) Centre National des Risques Industriels, 88, boulevard Lahitolle, 18020, Bourges, France

(C) Nexter Munitions, Engineering Direction, 7 route de Guerry, 18023 Bourges, France

(*)_obonnefoy@emse.fr

\begin{abstract}
.
One industrial process used by Nexter Munitions to manufacture pyrotechnical materials consists in preparing an emulsion of wax in TNT (2,4,6-trinitrotoluene) and adding Aluminium and ONTA (3-nitro-1,2,4-triazole-5-one) particles. When the suspension is homogeneous, it is allowed to flow by gravity through a pipe located at the bottom of the tank and to fill up a shell body. The suspension is characterized by a solid volume fraction of $53.4 \%$, which leads to high viscosities. In some circumstances, the emptying time is prohibitively long and the economic profitability is reduced. This study has been performed to make the emptying time lower with the constraint of unchanged volume fractions and grains mean diameter. So, we investigated the influence of the grain size distribution on the suspension viscosity. Different samples of Aluminium and ONTA have been used, with rather small differences in grain size distributions. The suspensions have been prepared in the industrial tank and the flow cast times measured. It has been observed that they differ by one order of magnitude. To avoid situations with too high emptying times, a procedure has been implemented to make prior characterization of the suspension rheology. Because of particles sedimentation and emulsion destabilisation, the classical Couette rheometer is not adapted. So, we designed and built a small size tank $\left(113 \mathrm{~cm}^{3}\right)$, where the suspension is continuously stirred and kept homogeneous. The measurement of the torque and rotational speed together with the use of the Couette analogy allowed us to observe an Ostwald fluid behaviour (flow consistency index $\mathrm{k}$, flow behaviour index $\mathrm{n}$ ). To gain in prediction, we established a correlation between the measured $(k, n)$ values and the grain size distributions. We characterized each suspension by the ratio of $\phi$ to $\phi_{m}$, where $\phi$ is the solid volume fraction (imposed by the commercial specifications) and $\phi_{m}$ is the maximum packing fraction. Because of the strong analogy between concrete and energetic paste, we chose the widely used De Larrard model to compute $\phi_{m}$. A linear dependance between the ratio $\phi / \phi_{m}$ and the indices $\mathrm{k}$ and $\mathrm{n}$ was observed. The second step was to provide an analytical expression for the flow cast time of a power-law suspension from a tank with a given geometry. Considering the large difference between the industrial inner tank diameter and the evacuation pipe diameter, we assumed that all the pressure drop was located in the evacuation pipe. Then, extending the Hagen-Poiseuille equation to Ostwald fluid, we were able to predict the emptying time with the knowledge of $\mathrm{k}$ and $\mathrm{n}$. Experimental and predicted emptying time are in very good agreement. This work helped the industrial manufacturer to divide the emptying time by a factor 12 .
\end{abstract}

Keywords: Concentrated suspension ; explosive materials ; Couette analogy ; Ostwald fluid ; maximum packing density ; De Larrard model ; Hagen-Poiseuille equation.

PACS: 82.70.Kj 


\section{Theory}

\section{Modified Hagen-Poiseuille Equation}

The Hagen-Poiseuille formula predicts the flow rate through a cylindrical tube for a given driving force (imposed pressure difference and/or gravitational volumetric force). The industrial tank, used to prepare XF13333 formulations, can be represented in a simplified way by Figure 1 where $\vec{g}$ is the acceleration due to gravity $\left(9.81 \mathrm{~m} \cdot \mathrm{s}^{-2}\right), R^{\prime}$ the internal radius of the tank $(\mathrm{m}), R$ internal radius of the outlet pipe $(\mathrm{m}), P_{2}, P_{1}$ and $P_{0}(\mathrm{~Pa})$ the pressures at the respective heights $H_{i}, H_{f}$ and $H_{0}(\mathrm{~m}), H(t)$ represents the height at time $t$ (s) and $h$ the height between $H_{f}$ and $H_{0}$.

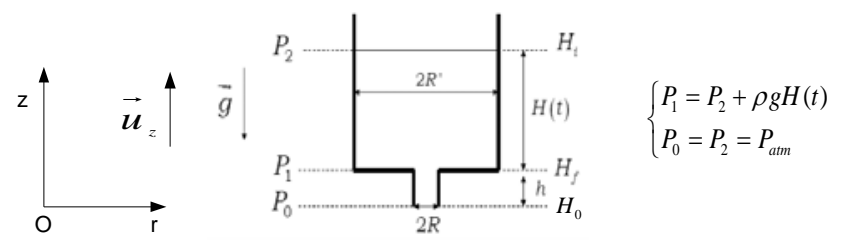

Figure 1: Schematic representation of the industrial tank.

From the general Navier-Stokes equation and in the configuration described by Figure 1, the viscous stress tensor can be written, in flow direction (for a projection on the axis $O_{z}$ ) and after integration following $r$ :

$$
\sigma_{r z}^{\prime}=\frac{r}{2}\left[\frac{\partial P}{\partial z}-\rho g z\right]
$$

For a power law type fluid, the viscous stress tensor can be written as:

$$
\sigma_{r z}^{\prime}=k\left(\frac{\partial v_{z}}{\partial r}\right)^{n}
$$

where $\mathrm{k}\left(\mathrm{Pa} . \mathrm{s}^{\mathrm{n}}\right)$ is the flow consistency index, $\mathrm{n}$ the flow behaviour index and $v_{z}$ the flow velocity along the axis $O_{z}$. Finally, after some simplifications, the volumetric flow rate $q$ $\left(\mathrm{m}^{3} / \mathrm{s}\right)$ of an Ostwald fluid in the configuration described by Figure 1 is given by the modified Hagen-Poiseuille equation:

$$
q=\frac{\pi n}{1+3 n}\left(\frac{1}{2 k}\right)^{1 / n}\left[\rho g\left(1+\frac{H(t)}{h}\right)\right]^{1 / n} R^{\frac{1+3 n}{n}}
$$

With Eq.(3), the emptying time t can be calculated.

\section{Maximum Packing Density Calculation}

The emptying time $\mathrm{t}$ of XF13333 suspensions is principally governed by the maximum packing density $\phi_{m}$ [1]. To calculate this parameter, the De Larrard model [3] is used because it appears to be the most adaptable to evaluate the compacity of our solid binary mixtures. For more details on the De Larrard model, interested readers can refer to his book [4].

\section{Experimental Set-up, materials and protocol}

To determine the correlation between the Ostwald parameters, $\mathrm{k}, \mathrm{n}$, and the maximum packing density $\phi_{m}$, five XF13333 suspensions, with different $\phi_{m}$ and same $\phi$ (equal to 53.4\%), are characterized using the unconventional "RheoXF" rheometer (see [5] for details and experimental protocol).

To compare experimental and theoretical emptying times, nine XF13333 formulations, with different $\phi_{m}$ and same $\phi$, are elaborated in the industrial tank. The time t required for $5700 \mathrm{~cm}^{3}$ of suspension to flow by gravity from the tank down to a shell body is measured [5]. 


\section{Results}

Correlation Between The Flow Consistency Index, The Flow Behaviour Index And The Maximum Packing Density

From the $\mathrm{n}$ and $\mathrm{k}$ experimental values for each ratio $\phi / \phi_{m}$, two linear correlations can be established.
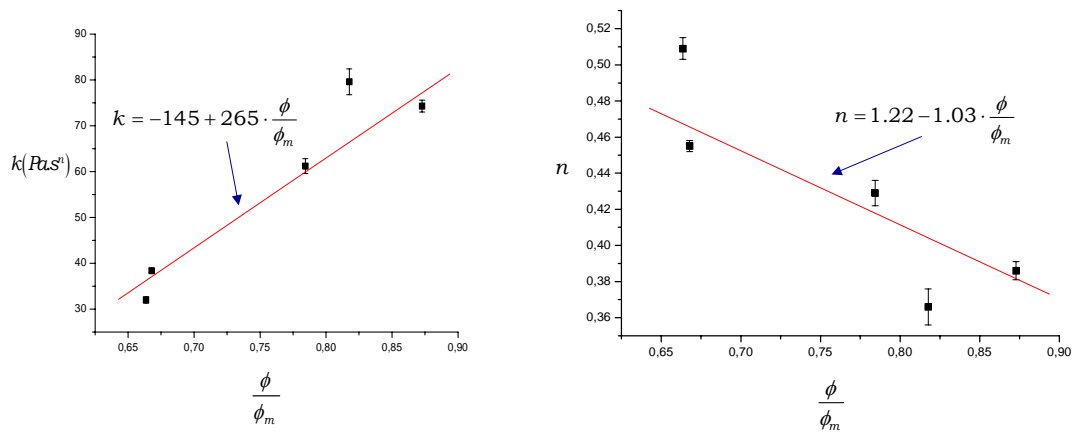

Figure 2. Correlation between $\mathrm{k}, \mathrm{n}$ and $\phi_{m} \phi / \phi_{m}$

Correlation Between The Flow Consistency Index, The Flow Behaviour Index And The Maximum Packing Density

To calculate the theoretical flow time t, the modified Hagen-Poiseuille equation (Eq.(3)) is used. As shown on Figure, an acceptable agreement is observed between experimental and theoretical results.

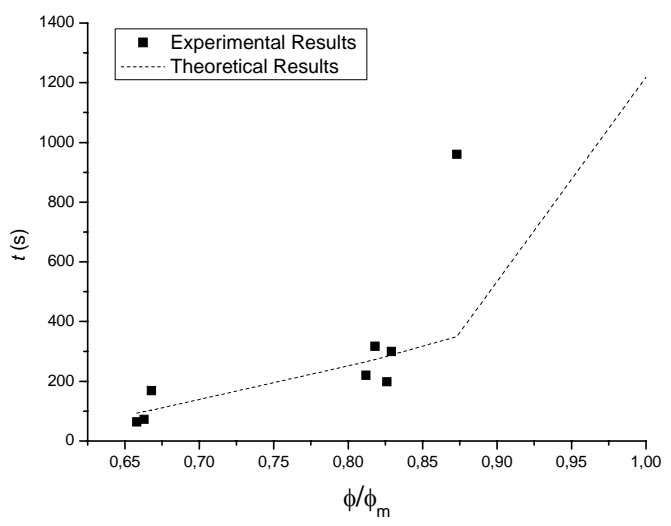

Figure 3. Correlation between the experimental flow time and the theoretical flow time calculated from the modified Hagen-Poiseuille equation.

\section{References}

[1] J.P. Guillemin, L. Brunet, O. Bonnefoy and G. Thomas, Propellants, Explosives, Pyrotechnics, 32, 3, 261-266, (2007).

[2] J.P. Guillemin, Y. Menard, L. Brunet, O. Bonnefoy and G. Thomas, J . Non-Newtonian Fluid Mech., doi:10.1016/j.jnnfm.2007, (2008).

[3] F. De Larrard and T. Sedran, Cement and Concrete Research. 32, 1699-1704, (2002).

[4] F. De Larrard, "Concrete Mixture-Proportioning - A Scientific Approach", in Modern Concrete Technology Series-1999, N9 , edited by E \& FN SPON, London.

[5] J.P. Guillemin, "Rheology of concentrated suspensions of recyclable energetic materials - Flow time model”, Ph.D. Thesis, Ecole Nationale Supérieure des Mines de Saint-Etienne, 2008. 